\title{
A SHELTER FOR THE VICTIMS OF THE TYPHOON HAIYAN IN THE PHILIPPINES: THE DESIGN AND METHODOLOGY OF CONSTRUCTION
}

\author{
${ }^{1}$ Danilo RAVINA, ${ }^{2}$ Rowell Ray SHIH \\ Department of Architecture, School of Architecture, Fine Arts and Design \\ University of San Carlos, Cebu City, Cebu, Philippines \\ e-mail: ${ }^{1}$ dravina@yahoo.com, ${ }^{2}$ rowellshih@yahoo.com
}

Received 10 December 2016; accepted 8 April 2017

\begin{abstract}
In 2013 Typhoon Haiyan, the largest typhoon ever recorded in the Philippines, devastated several portions of the country. This resulted in more than 7,000 deaths and thousands of people were misplaced or were made homeless. The aim of this study is to design and produce a transitional shelter prototype, for the victims of typhoon Haiyan. The shelter is affordable, easy to construct using basic tools and that can provide maximum space for a family of five while being able to withstand an onslaught on another incoming typhoon. Furthermore, this paper presents a design concept for a transitional shelter incorporating the Bent Method of construction while only using locally sourced coco lumber and actual validation on a full scale prototype. In order to achieve this objective, site analysis as well as consultations and interviews with the victims were being done and the results evaluated. Second, the conceptual designs as well as the method are presented to the local government and the beneficiaries of the shelter to obtain feedback. Third, the construction of a prototype was then employed to evaluate the construction conditions as well as the spatial considerations for the users. The proposed shelter used only locally sourced materials, manpower and simple tools for a family of five members. Finally, a post evaluation analysis was conducted in order to obtain feedback on the performance of the shelter and provide future knowledge in improving the design and its use. This study shows how due to the design of the shelter, the families were able to develop their own spaces as well as make subtle design alterations according to their expanding needs. Results from these studies reveal that by understanding the needs of the users, the design and methodology of the 'I-Siguro $D a-a n '$ transitional shelter was effective and practical in providing temporary housing for the victims of the typhoon.
\end{abstract}

Keywords: Transitional shelter, Bent construction method, Participative design outcomes 


\section{Introduction}

On November 2013 the Philippines was devastated by super typhoon Haiyan. With an average wind speed of $300 \mathrm{~km} / \mathrm{h}$, it devastated the islands of Leyte, Samar, Bohol and northern Cebu [1]. The typhoon caused extreme economic damages, left thousands of people homeless while killing at least 7,000 people. Since then, there has been a conscious effort in the construction of more resilient housing for the underprivileged victims of the community. While there are numerous factors to be considered when designing these types of shelters, knowing the needs and wants of the affected families is sometimes ignored [2]. International donors too often ignore the complexity of the local conditions and disregard the local manpower and existing materials of the affected community. Most often the design of these housing units can be too complex or requires highly skilled workers [3].

During these disasters, the United Nations acknowledged that one of the many 'mistakes' that had been made was the lack of consultation between the victims [4]. Without proper consultation, the victims became mere spectators of the work that was carried out rather than participants [5]. The performances of these shelters are sometimes hindered by insensitivity to the local culture, climate and social issues which can result in further delays [6]. This results in producing expensive and extraneous looking shelters, which eventually results in the abandonment by the affected families. By recognizing the needs of the affected families and reviewing the local conditions, the recommended shelters will consequently bring social, economic, cultural and environmental benefits for the affected community. Community participation is therefore important because the affected families will have a sense of pride and ownership once the shelter is turned over to them. This study adopted the community participative design approach method in the design of the transitional shelter. By using this approach and the knowledge of the local people, who over the years have developed their own technical solutions and adapted their own context will the shelters be accepted as part of their own community. This study therefore introduces new design concepts for climate resilient transitional shelter, which was developed as part of a community extension program organized by the University of San Carlos School of Architecture and Fine Arts, in cooperation with the Institute of Planning and Design. The beneficiaries of the proposed shelter are the communities in Daanbantayan, at the northern part of Cebu (Philippines), which was highly affected by the onslaught of typhoon Haiyan. The first author, who was the main architect, decided to name these shelter 'I-Siguro Da-an', which is a Cebuano vernacular term that means 'To Secure First'. This was the title borne out of the idea of creating a transitional shelter for typhoon Haiyan victims.

\subsection{Transitional shelters}

After the onslaught of natural disasters, the typical response by humanitarian organizations and the local government is to allocate basic shelter materials like tents and plastic sheeting with some basic tools. This has many advantages, which include ease of transportation, cheap and speed, however this is not intended to offer long term shelter for the affected communities. However, if shelters are transitional - meaning 
capable of being disassembled, upgraded, reused, relocated and recycled in different configurations for alternative functions - they offer the opportunity to link relief and future development perspectives towards a sustainable solution. From the emergency to rehabilitation and reconstruction, transitional shelters can provide shelters for the affected community while providing social and economic recovery throughout the development process [7]. This transformational capacity and the reuse potential of individual components make transitional shelters more sustainable over their life-cycle than conventional solutions which become obsolete, are often removed, disposed of, or abandoned when a transition is made from one relief phase to the next. Thus, transitional shelters have been embraced by numerous humanitarian agencies and have sheltered many affected communities worldwide [8]. Additionally, transitional shelters should serve the affected community for many months or even years, if possible [9].

\section{Methodology}

Data collection occurred over two separate site visits to the disaster affected areas of Daanbantayan between November 2013 and December 2013. These data were collected using discussions with the affected families as well as the local government, community leaders and current residents. The research team also conducted direct site interpretations and analysis. In addition, the key features of the shelter should be:

(i) Can be easily relocated;

(ii) Can be easily upgraded, and

(iii) Constructed of local and re-usable materials.

In order to design a housing unit, which is easily acknowledged by the community, the community participation approach was being used. Beneficiaries and the affected families were being consulted and their needs and wants were being taken into consideration. Empowering beneficiaries in these types of housing projects play an important role because the community members become part of the political process and thus have a voice in the decisions of the community [10]. By including the community in the process, the cost can be reduced, allowing restricted resources to be spread among more of the affected families [11]. Design influences can define the performance of the shelters and it is through consultation with the communities involved which can prevent economic, environmental and socio-cultural problems which may arise in the future [2]. After the survey, it was being decided that the housing unit will be provided for a family of five. Furthermore, $80 \%$ of the families affected include the father, mother, grandparent and two children. The 'reverse-engineering' methodology was being used in order to offer a design solution for the shelter, this means starting with the structural aspect of the shelter and applying the architectural principles later (Fig. 1). The advantage of using this methodology is that the structural components are clearly being focused early in the design and therefore structural failures can be clearly identified early during the design process. 


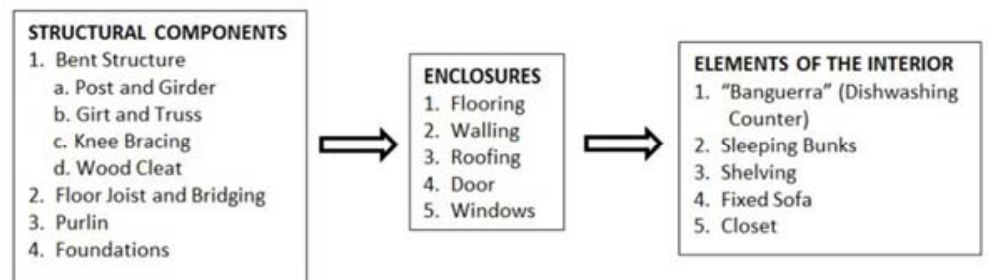

Fig. 1. The design process of the proposed transitional shelter

\section{Materials}

The shelter design must be flexible enough on the use of construction materials and allow replacement with alternatives. A large scale transitional shelter construction project requires large volumes of materials that may negatively impact on the local environment. Large timber requirement may adversely affect the forest environment and the total components should be limited to allow for easy transportation [12]. Alternate steel material may offset this imbalance. It is therefore suggested that the shelters be made of materials that can easily be reused and upgraded instead of being easily disposed [13]. In the Visayas region coco lumber is readily available and is the staple construction material being used by the local community because it is abundant and cheap to acquire. However, 4"x4" for the post is difficult to come by, so the basic dimension to be used shall be 2"x4" and 2"x6" with lengths at 8' and 10'. These types of wooden houses must be rapidly available and must draw on local resources and industries [8]. This lesson was learned after the Kalamata earthquake in Greece in which the prefabricated temporary houses for the affected families were donated by the international community; however, delays in the delivery meant that temporary housing was not readily available.

\subsection{Technical description}

The amount of covered living space that a transitional shelter must provide is a critical determinant of the design, logistic requirements and cost. A minimum of 12 square meters of covered living space is assumed based on a family of 5 with 2.40 square meters per person occupant density. This can be expanded into 18 square meters by an addition of a 6 square meter module. Fig. 2 illustrates the geometry of the shelter. This configuration has a rectangular floor plan of $4.7 \mathrm{~m} \mathrm{x} 2.4 \mathrm{~m}$ with a total height of 3.5 meters, measured up to the apex of the roof. The design of the shelter is based on the Bent Method of construction which essentially consists of a series of structural frames called 'bents' to which the flooring system, roofing system as well as the interior and exterior walls are fastened and tied down (Fig. 2a). Furthermore, the walls or skins are non-structural and act mainly as a means of giving rigidity to the bents and enclosing the house (Fig. 2b). The bents can be pre-fabricated or constructed in situ. Additional diagonal braces are added on all sides for protection whiles its slanted walls, it maximizes space inside for sleeping and household chores for the family. The roof of the shelter is not extended to prevent the roof from tearing during strong winds. The 
simplicity of the design allows for the reduction of training period of the construction workers and resources which can lead to delays (Fig. 3). The shelter is made up of bamboo and coconut lumber, materials which are readily available in case of modifications by the family. There are currently two (2) types of shelters:

(i) The Lipak version, of which consists of bamboo slits (Fig. 4a); and

(ii) The Amakan version, of which consists of the native material called Amakan (Fig. 4b).

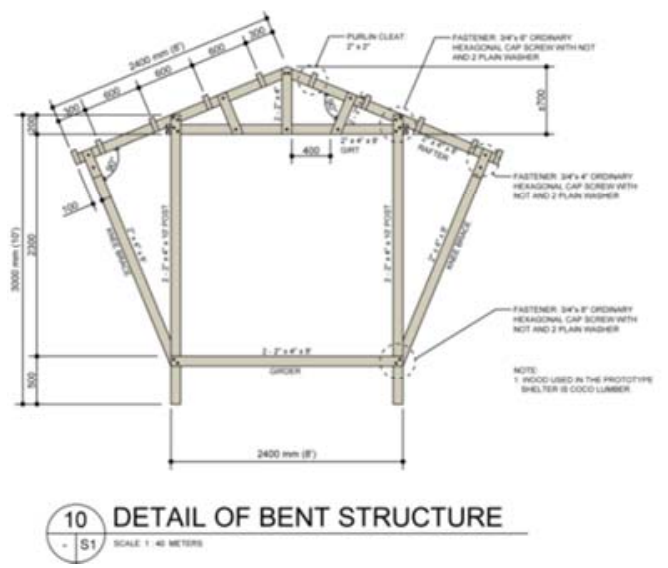

a)

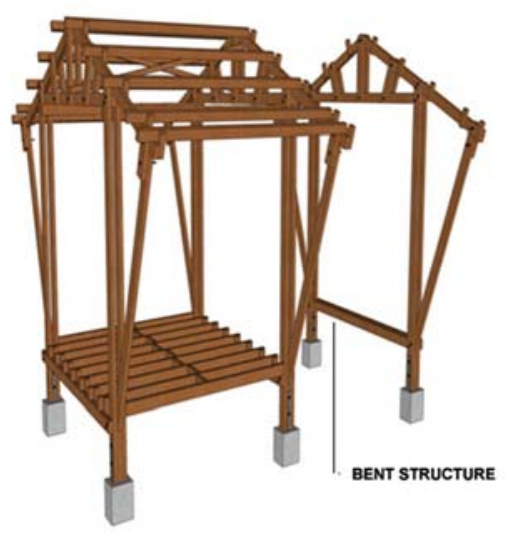

b)

Fig. 2. Detail of the Bent Structure

$b+b^{b} b^{b}$
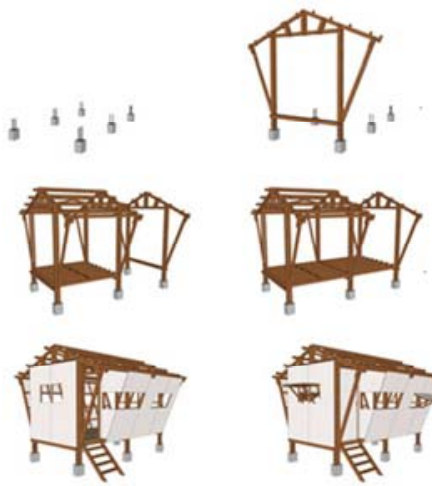
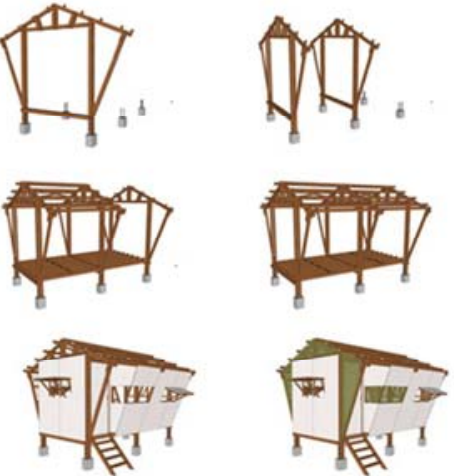
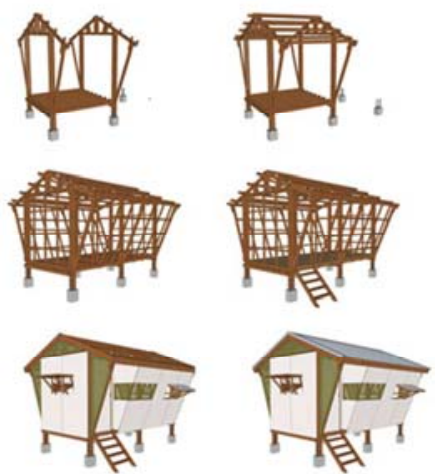

Fig. 3. The construction process

The form and plan (Fig. 5) of the shelter evokes a seemingly modern 'nipa hut', the traditional residential shelter in the Philippines, that somehow blends well with cultural appropriateness. 


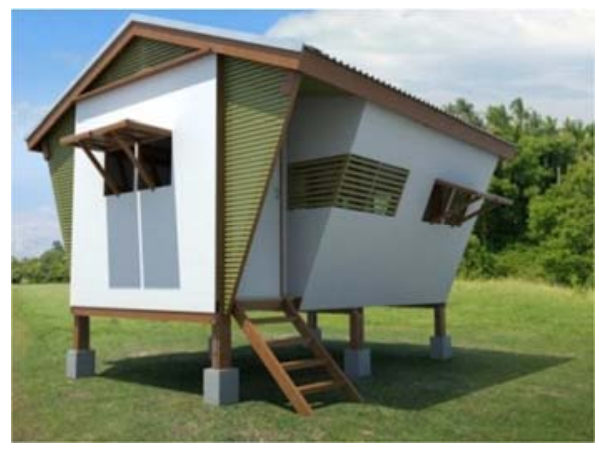

a)

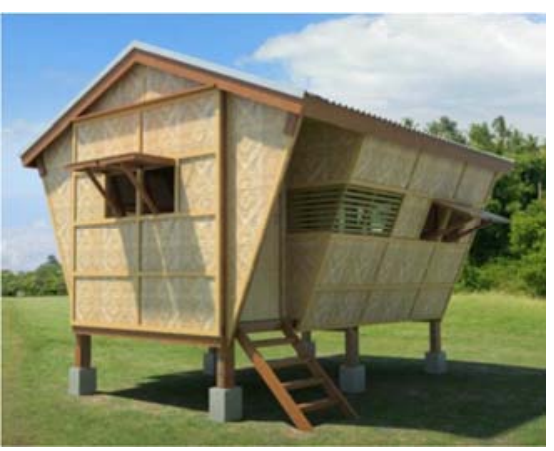

b)

Fig. 4. Two versions of the shelter: a) Bamboo Slit and b) Amakan

The simple roof plan has a $30^{\circ}$ inclination to allow for rainwater to slide off and harvested while reducing the impact of strong winds. The design encourages passive cooling and allow for maximum ventilation for the users. Shelters which accentuate natural ventilation which is essential for hot-humid climates like the Philippines [14]. Prominent feature of the form are the slanted walls in the longer sides of the house. These canted walls offer four advantages, which are:

1) They lessen wind resistance and deflect airflow, although this is still subject for wind analysis in further studies;

2) The slanted design of the walls allows it to shade itself from the sun during the overheating period from 9:00 in the morning to 15:00 in the afternoon. It also eliminated overhangs and thus prevents the 'Monroe' effect caused by wind updraft;

3) Creates a sense of wider interior spaces;

4) In the event of a further disaster, the wall will simply fall outward and thus minimize serious injury to the occupants.

The crawl space serves a multipurpose function for domesticated animals, storage space and as play space for the children. In the interiors, the volumetric space becomes bigger as the walls lean outward. This generates a practical and usable anthropometrics because movement and perception of a person becomes wider from the hips to the extended arms and the eyes (for visual expanse). The leaning walls also offer opportunity to attach shelves that do not encroach into the established floor footprint in the Living Module (Fig. 6a). At the Sleeping Module (Fig. 6b), bunk beds can be made at the sides allowing two persons to sleep above floor level and make 3 to 4 persons to sleep comfortably on the floor. Ventilation flow through is achieve via awning windows at the front, rear and side walls. Table I shows a summary of the design features and the participative process of the proposed shelter. 


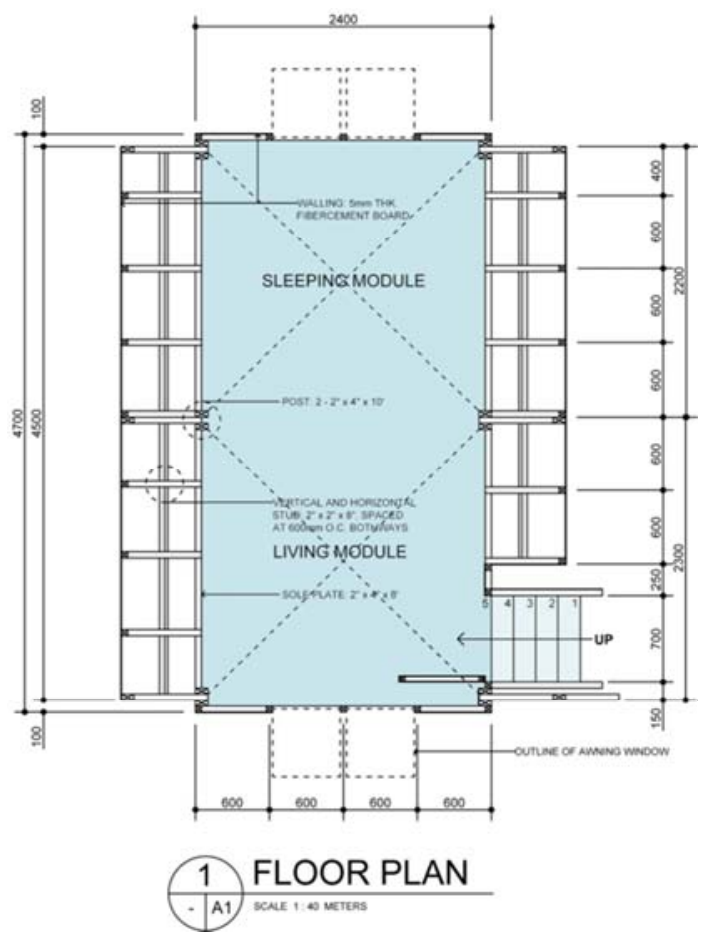

Fig. 5. Floor plan

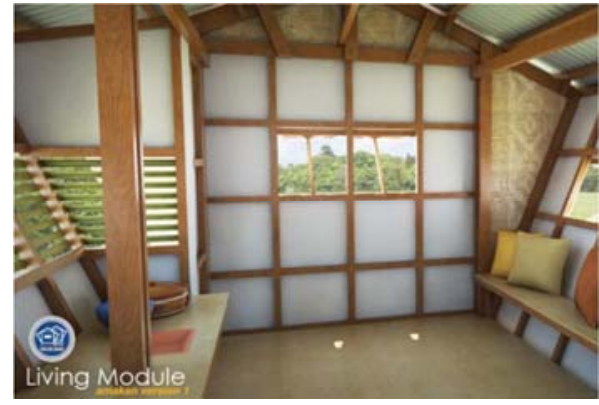

a)

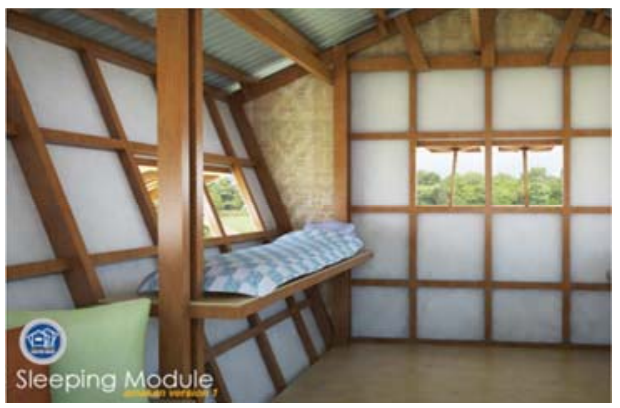

b)

Fig. 6. The a) living module and b) sleeping module interior view

\section{Project outcome}

With the help of different Non-Government Organizations (NGO's) like Dr. Fritz Strolz and his wife Pearle Strolz of the Swiss Rotary of Switzerland (Fig. 7), Movement for a Livable Cebu (MLC), JPIC-IDC, OM Philippines and the Ramon Aboitiz 
Foundation (RAFI) close to 500 units have already been successfully constructed (Table II).

\section{Table I}

The design and participative process of the 'I-Siguro Da-an' Shelter

\begin{tabular}{|c|c|}
\hline \multicolumn{2}{|l|}{ Design Features } \\
\hline Foundations & Reinforced concrete on all foundations \\
\hline Reinforcements & $\begin{array}{l}\text { Tied down from bottom-up. Additional wooden diagonal braces } \\
\text { on all sides }\end{array}$ \\
\hline Roof type & Simple Hip roof ( $30^{\circ}$ inclination) for easy rain flow \\
\hline Shape & Simple rectangular shape for easy construction \\
\hline $\begin{array}{l}\text { Flood preventive } \\
\text { measures }\end{array}$ & On stilts to avoid flooding and protection from other elements \\
\hline Materials & Locally available, re-usable materials \\
\hline Portability & Can be relocated and easily upgraded \\
\hline No. of occupants & $\begin{array}{l}\text { For a family of five (5), which is the average family size of the } \\
\text { affected community }\end{array}$ \\
\hline Ventilation & Cross ventilation from all sides (side, bottom, top) \\
\hline $\begin{array}{l}\text { Community } \\
\text { participation }\end{array}$ & $\begin{array}{l}\text { Affected communities and local government units are involved } \\
\text { with the design process }\end{array}$ \\
\hline Evaluation & $\begin{array}{l}\text { Post occupancy evaluation and surveys with the beneficiaries for } \\
\text { future design improvement }\end{array}$ \\
\hline Total Area & 12 square meters \\
\hline
\end{tabular}

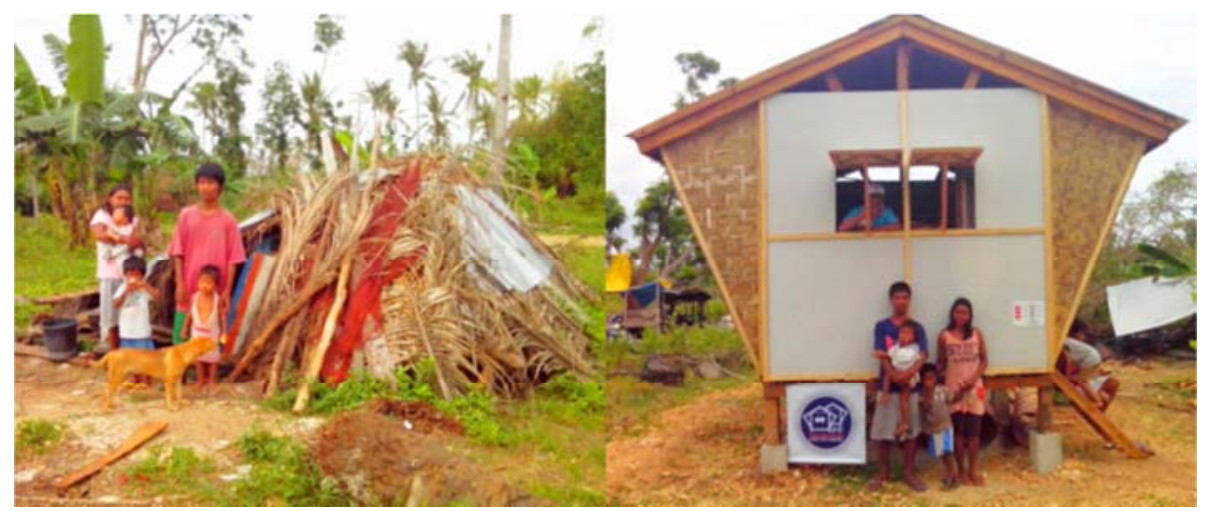

Fig. 7. The first beneficiaries of the transitional shelter through the efforts of Dr. Frtiz Strolz Rotary of Switzerland

These shelters are mostly in the northern parts of Cebu where much of the damage has been done by the typhoon, however there are also shelters being built on the neighboring Bohol Island. In a few months after the families received their new homes, the research team went back to assess the performance of the shelters. The main objective of this evaluation was to identify and evaluate critical aspects of the performance of the shelter. This will allow the research team to identify problem areas of the structure and thus to be able to build better design guidelines in the future. 
Studies were also being made on how the families utilize the space and a survey was done on the various performance of the shelter. It was observed that the families are finding various ways to expand the shelter.

\section{Table II}

The benefactors and the 'I-Siguro Da-an' shelters built since January 2017

\begin{tabular}{|l|l|l|}
\hline \multicolumn{1}{|c|}{ Mission Areas } & \multicolumn{1}{|c|}{ Benefactors } & \multicolumn{1}{c|}{ Built } \\
\hline San Remigio & Swiss Rotary Club \& CICM & 202 \\
Daan Bantayan & MLC \& Rotary Club Cebu Fuente & 6 \\
Bantayan Island & Swiss Rotary Club \& KCI & 20 \\
Bohol (Ubay Island) & JPIC-IDC \& ILO & 42 \\
Medellin & OM Philippines & 220 \\
Cebu (Badjao Ritual House) & RAFI & 6 \\
& Total & $\mathbf{4 9 6}$ \\
\hline
\end{tabular}

The sloping roof allowed for extended extensions and thus families can get more space (Fig. 8a). Most of the families have also used the abundant space under the shelter for various farm animals (Fig. $8 b$ ).

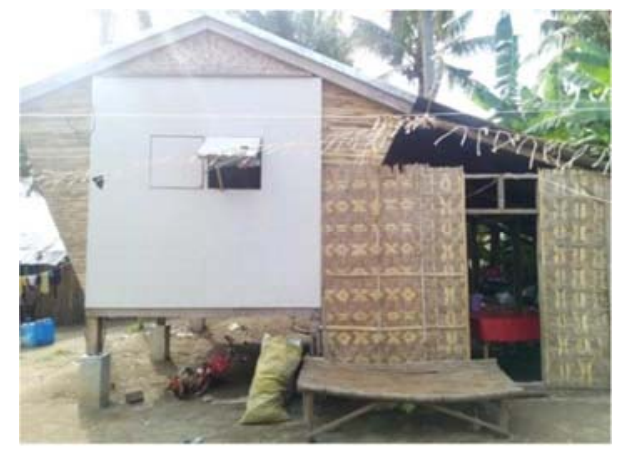

a)

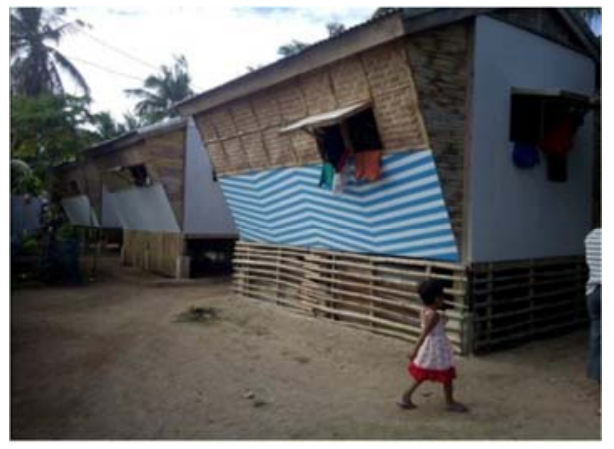

b)

Fig. 8. The inclined roof allowed for an extended overhang, a) for various family activities and the ample space below the shelter, b) became storage for various farm animals

In the consultation with the families, there was increased user satisfaction mainly due to the involvement that the community had in the final design of the shelter. This meant that the beneficiaries were not just passive victims receiving humanitarian aid but responsible for their own shelter project. Presently, the shelter units were still in used and lasted much longer than they were needed as a mere 'transitional' shelter. The length of time this transitional shelter is needed will highly depend upon the ability of the local government in trying to construct the permanent housing program for the affected families. Further experimental testing was still being done in the field to determine the effectiveness and durability of the proposed transitional shelter. 


\section{Conclusion}

This study demonstrates two important findings. First, it was able to demonstrate the design and methodology of a transitional shelter using the bent construction method while incorporating locally sourced materials. By using this approach, the shelter can be swiftly constructed and immediately be turned over to the affected families. By using locally sourced construction materials, the local labor can be improved while promoting local manufacturers and suppliers. Second, by consulting and participating with the affected community in the design process, assessing the local conditions and studying the user's needs and potentials, the designers were able to successfully produce a shelter that the affected community can call one of their own. This user-point of view process will avoid producing expensive and alien-looking shelters, which usually can result in abandonment and user dissatisfaction in the future. International donors, while their intentions are good, too often ignore the complexity of the local conditions and the user's needs. The design and living standards must reflect the local living standards of the community rather than the standards of the donor country. Furthermore, from a design-oriented view, this study also presented that the design of the shelter helped improve the lives of the affected families. The design of the shelter allows for expandability according to the needs of the families. Since the shelter was elevated above the ground, the space underneath can be used as storage for various small farm animals. The sloping roof allows the family to extend the spaces for various activities. The actual intention of the transitional shelter was to provide temporary housing for the affected communities, however since the government still has to finish constructing the permanent housing units, the families were still able to use the shelter beyond the allowable given time.

\section{Acknowledgements}

This work has been undertaken as part of a community project by the University of San Carlos School of Architecture, Fine Arts and Design (Institute of Planning and Design). IPD is headed by Architect Danilo Ravina (first author) while additional data was also provided by Architect Bryan Auman.

\section{References}

[1] Mori N., Kato M., Kim S., Mase H., Shibutani Y., Takemi T., Tsuboki K., Yasuda T. Local amplification of storm surge by Super Typhoon Haiyan in Leyte Gulf, Geophysical Research Letters, Vol. 41, No. 14, 2014, pp. 5106-5113.

[2] Bashawri A., Garrity S., Moodley K. An overview of the design of disaster relief shelters, Procedia Economics and Finance, Vol. 18, 2014, pp. 924-931.

[3] Farzaneh H., Fallahi A. Temporary housing responds to disasters in developing countries, Case study: Iran-Ardabil and Lorestan Province earthquakes, World Academy of Science, Engineering and Technology, Vol. 66, 2010, pp. 1536-1542.

[4] Davis I. Shelter after disaster, Oxford Polytechnic Press, 1978.

[5] Norton R. Disasters and settlements, Disasters, Vol. 4, No. 3, 1980, pp. 339-347. 
[6] Félix D., Branco J. M., Feio A. Temporary housing after disasters: A state of the art survey, Habitat International, Vol. 40, 2013, pp. 136-141.

[7] Mira L. A., Thrall A. P., De Temmerman N. Deployable scissor arch for transitional shelters, Automation in Construction, Vol. 43, 2014, pp. 123-131.

[8] Davidson C. H., Johnson C., Lizarralde G., Dikmen N., Sliwinski A. Truths and myths about community participation in post-disaster housing projects, Habitat International, Vol. 31, No. 1, 2007, pp. 100-115.

[9] Davis, Ian. What have we learned from 40 years' experience of Disaster Shelter? Environmental Hazards, Vol. 10, No. 3-4, 2011, pp. 193-212.

[10] Ferguson B., Navarrete B. A financial framework for reducing slums: Lessons from experience in Latin America, Environment and Urbanization, Vol. 15, No. 2, 2003, pp. 201-216.

[11] Aysan Y. Disasters and the small dwelling, Perspectives for the UN IDNDR, Ian Davis (Ed) James \& James, London, 1992.

[12] Sener S. M., Altun M.C. Design of a post disaster temporary shelter unit, Istambul Technical University Journal of Faculty of Architecture, Vol. 6 No. 2, 2009, pp. 58-74.

[13] Kats G., Alevantis L., Berman A., Mills E., Perlman J. The costs and financial benefits of green buildings, A Report to California's Sustainable Building Task Force, USA, 2003.

[14] Ashmore J. Tents: a guide to the use and logistics of family tents in humanitarian relief, Geneva, UN, 2004. 